\title{
ПРЕДВЫБОРНЫЕ КАМПАНИИ КАНДИДАТОВ В ПРЕЗИДЕНТЫ РОССИЙСКОЙ ФЕДЕРАЦИИ (2017-2018 ГГ.)
}

\author{
E. B. Махора \\ Московский гуманитарный университет
}

Аннотация: В статье анализируются предвыборные программы и кампании кандидатов в Президенты Российской Федерации в 2018 году.

Ключевые слова: предвыборная программа; предвыборная кампания; Президент; выборы

\section{ELECTION CAMPAIGNS OF CANDIDATES FOR THE PRESIDENT OF THE RUSSIAN FEDERATION (2017-2018)}

\author{
E. V. Makhora
}

Moscow University for the Humanities

Аннотация: The paper analyses the election programmes and campaigns of the candidates for the presidency of the Russian Federation in 2018.

Keywords: election programme; election campaign; President; election

Выборы Президента страны - это важная сторона жизни общества. От выбора каждого гражданина зависит, какой будет политический курс в стране. Предвыборные кампании кандидатов в Президенты неотъемлемая часть процедуры выборов.

Несмотря на то, что согласно социологическому опросу Всероссийский центр изучения общественного мнения (ВЦИОМ) около 70\% граждан страны планировали отдать свой голос за действующего Президента В. В. Путина, для политологов особый интерес представляют собой предвыборные кампании всех кандидатов в Президенты, поскольку их предвыборные кампании включают в себя варианты решения насущных проблем в обществе. Кроме того, так как для ряда кандидатов это было первое выдвижение в кандидаты в Президенты, возможно, в будущем кто-то из них станет значимой политической фигурой в жизни страны. 
Цель статьи заключается в выявлении эффективности составления предвыборных программ и проведения предвыборных кампаний кандидатами в Президенты.

18 декабря 2017 г. был дан старт избирательной кампании (В России официально, 2017: Электр. ресурс).

В бюллетене кандидаты должны быть перечислены в алфавитном порядке. Таким образом, бюллетень на выборах 18 марта 2018 года выглядел следующим образом:

1) С. Н. Бабурин, «Российский общенародный союз»,

2) П. Н. Грудинин, партия КПРФ,

3) В. В. Жириновский, партия ЛДПР,

4) В. В. Путин, самовыдвижение,

5) К. А. Собчак, партия «Гражданская инициатива»,

6) М. А. Сурайкин, партия «Коммунисты России»,

7) Б. Ю. Титов, «ПАРТИЯ РОСТА»,

8) Г. А. Явлинский, партия «Яблоко» (ЦИК завершил регистрацию кандидатов в президенты, 2018: Электр. ресурс).

B. В. Путин трижды участвовал в качестве кандидата в Президенты (и трижды выигрывал). В. В. Жириновский пять раз становился кандидатом в Президенты, Г. А. Явлинский - дважды. С. Н. Бабурин, П. Н. Грудинин, К. А. Собчак, М. А. Сурайкин, Б. Ю. Титов впервые стали кандидатами на пост Президента (Гаврилко-Алексеев и др., 2017: Электр. ресурс).

Далее целесообразно проанализировать предвыборные программы кандидатов в Президенты.

1) С. Н. Бабурин. С. Н. Бабурин в своей предвыборной кампании заявлял о планах внести изменения в Конституцию Российской Федерации и к подходу к внешнеполитическим отношениям. Кроме того в предвыборной кампании кандидата в президенты содержался пункт о разработке ряда законов, позволяющих снять с России нефтяную зависимость. Гражданам страны политик, в случае его избрания президентом, обещал сделать бесплатными сферу обслуживания и образование, усилить контроль за жилищно-коммунальными хозяйствами, за процессами миграции (Сергей Бабурин, 2018: Электр. ресурс).

2) П. Н. Грудинин. П. Н. Грудинин в своей предвыборной кампании опирался на программу партии КПРФ, а также на краткий свод предвыборных тезисов партии под названием «10 шагов к достойной жизни».

Среди конкретных мер, способных привести к поставленным целям, перечислялись национализация природных ресурсов и стратегических отраслей народного хозяйства, государственный контроль цен на товары первой необходимости. 
Важным обстоятельством является, что по ряду пунктов программы партии КПРФ и партии ЛДПР пересекались, например, по вопросу введения прогрессивной шкалы налогообложения.

Несмотря на идеологические различия, программы партии КПРФ и партии ЛДПР выдержаны в схожей тональности, считают эксперты.

По мнению политолога В. Л. Шаповалова, сложилась достаточно парадоксальная ситуация: с одной стороны, ЛДПР всегда позиционировала себя как антикоммунистическая партия, и она возникла на волне антикоммунистических настроений. Но, с другой стороны, ЛДПР, несмотря на это, уделяет большое внимание социальным вопросам (Программные заявления, 2017: Электр. ресурс).

3) В. В. Жириновский. В основе программы В. В. Жириновского большое внимание уделялось вопросам политических свобод и несправедливого распределения доходов.

Вероятно, наиболее оригинальный подход В. В. Жириновский демонстрировал в идеологической и внешнеполитической сферах: например, он намерен приложить усилия для исторического примирения «белых» и «красных» (Программные заявления, 2017: Электр. ресурс).

4) В. В. Путин. Политолог М. Е. Карягин отмечает, что главной особенностью выборов Президента в 2018 году является то, что, судя по социологическим опросам, заранее известно, что у В. В. Путина были очень большие шансы на победу.

После общекрымского референдума в 2014 году, по данным того же ФОМа, рейтинг В. В. Путина достиг $74 \%$, и с тех пор ниже $62 \%$ не опускался. Сейчас же он составляется около 70\%.

Таким образом, вероятно, не было даже гипотетического сценария, при котором В. В. Путин, приняв участие в выборах, проиграл бы их.

Для сравнения в 2012 г. у В. В. Путина также был высокий рейтинг. Однако, победа В.В. Путина на выборах не была очевидной так как его рейтинг, по данным ФОМ, находился на уровне 49\%, что не исключало теоретической возможности второго тура.

Если проанализировать действия В. В. Путина и акценты, которые были им выставлены, то в этом политическом цикле ставка делалась на молодежь и новые технологии. Например, встречи В. В. Путина с молодыми и перспективными школьниками и студентами, а также организацию конкурса «Лидеры России», выполняющий функцию социального лифта (Карягин, 2017: Электр. ресурс).

Необходимо отметить, что при проведении предвыборной кампании на выборах Президента в 2012 г. В. В. Путин также проводил встречи с рабочими, представителями технической интеллигенции, науки, студенчества. 
В теледебатах в 2012 г., также, как и в 2018 г. В. В. Путин не принимал участие.

Среди тех, кто призывал голосовать за В. В. Путина, было много лидеров общественного мнения (Саитова, 2013: 268). Например, ректор Московского гуманитарного университета И. М. Ильинский был доверенным лицом В. В. Путина на выборах Президента в 2012 г. Он обосновал свою позицию следующим образом: «Я всего лишь отдаю должное его делам и заслугам, которые он уже совершил, - с надеждой в то, что опыт и знания, которые он приобрел, позволят ему работать лучше» (Ильинский, 2012: 6).

Таким образом, можно сделать вывод, что В.В. Путин на протяжении двух предвыборных кампаниях применял крейсерскую стратегию. Данный вид стратегии больше всего применяется теми кандидатами, которые являются однозначными лидерами с самого начала кампании и стремящимся сохранить свои позиции в ходе проведения всей кампании. (Булак, 2013: 261).

5) К. А. Собчак. К. А. Собчак вторила Г. А. Явлинскому, призывая «прекратить гибридную войну» на востоке Украины, а также вернуть домой военнослужащих, находящихся «в любом статусе» за рубежом.

По мнению политолога В. Л. Шаповалова, хотя К. А. Собчак позиционировала себя как кандидата «против всех», в действительности она будет конкурировать с Г. А. Явлинским за тот процент граждан страны, выступающих за пересмотр крымского референдума. В. Л. Шаповалова предполагал, что между ними развернётся жёсткая конкуренция (Программные заявления, 2017: Электр. ресурс).

6) М. А. Сурайкин. М. А. Сурайкин применил в своей предвыборной кампании, по сути, ту же самую программу, с которой его партия в 2016 г. пыталась пройти в Государственную думу. Она называется «Десять сталинских ударов», нацеленных на возвращение в России социалистического строя.

Так, в случае прихода к власти партия «Коммунисты России» обещала провести национализацию банковской системы, базовых отраслей экономики, в том числе горнодобывающую промышленность и энергетику, ЖКХ, ввести госмонополию на алкоголь и табачную продукцию (Максим Сурайкин, 2018: Электр. ресурс).

7) Б. Ю. Титов. Свой электорат Б. Ю. Титов определил как людей, вовлеченных в предпринимательство, и предположил, что их число составляет 20-25\% от взрослого населения страны. Главные идеи его предвыборной программы Б. Ю. Титова - расширение экономических свобод, поддержка малого и среднего бизнеса, независимое судопроизводство, гарантии собственности, декриминализация экономической деятельности.

В основу предвыборной программы легла созданная совместно со Столыпинским клубом «Стратегия роста», и президентские выборы Б. Ю. Ти- 
тов рассматривает как референдум о доверии этой программе (Кандидат на вырост, 2017: Электр. ресурс).

8) Г. А. Явлинский. Предвыборная программа Г. А. Явлинского носила название «Дорога в будущее». Однако, первые же пункты документа апеллируют в большей степени к иностранным государствам, нежели к реальным интересам российских граждан.

По мнению экспертов, Г. А. Явлинский не рассчитывал на победу, своими высказываниями и действиями на протяжении последних десятилетий политик подорвал шансы на лидерство.

Как отметил политолог В. Л. Шаповалов, Г. А. Явлинский и прежде во главу угла ставил вопросы внешнеполитические - и в программе партии «Яблока», и в своих публичных выступлениях (Программные заявления, 2017: Электр. ресурс).

Далее рассмотрим основные этапы предвыборных кампаний.

Публичной политической рекламы на первом этапе предвыборной кампании по выборам Президента практически не было, материалы в основном присутствовали только в СМИ и социальных сетях, билборды в поддержку кандидатов стали появляться лишь в конце января, а немногие печатные агитматериалы этого периода одинаковы для всей страны и не учитывают региональную составляющую.

КГИ в своем докладе о предвыборных кампаниях в 2018 г. отметил почти полное отсутствие публичной политической рекламы на первом этапе кампании. При этом доминировала косвенная агитация под видом освещения профессиональной деятельности кандидата.

Агитационных печатных материалов штабы кандидатов фактически не выпускали, Даже в ходе сбора подписей кандидаты не распространяли материалы о себе, что является уникальным случаем. Почти отсутствовала и наружная политическая реклама (В России не ведется активной агитации, 2018: Электр. ресурс).

Дебаты на выборах Президента проходили в новом формате. Теперь все участники предвыборной гонки посещали студию и отвечали на вопросы ведущего. Такой формат, по мнению политолога А. Р. Галлямова, был выбран специально.

Нельзя сказать, что кандидаты в Президенты эффективно применили свое участие в теледебатах: кроме общих фраз по своим предвыборным программам, они особенно ничего не сказали и, вероятно, мало чем запомнились избирателям.

Не раз претензии участников дебатов и ЦИК России касались того, что кандидаты часто присылали вместо себя доверенных лиц (Теледебаты, 2018: Электр. ресурс). 
ВЦИОМ проводил еженедельные (с 18 февраля по 09 марта 2018 г.) измерения электоральных предпочтений: опросов о намерениях россиян участвовать в голосовании и еженедельные рейтинги политиков, которым население готово отдать свои голоса на предстоящих выборах.

В ходе опросов гражданам страны был задан вопрос: «Если бы президентские выборы проводились в ближайшее воскресенье и список выглядел бы следующим образом, то за кого из этих кандидатов Вы бы, скорее всего, проголосовали? Вы можете дать один ответ».

Необходимо отметить, что на протяжении всего проведения опроса результаты были очень стабильные.

В ответ на вопрос за В. В. Путина скорее всего проголосовали бы от $69 \%$ до 70\%; за П. Н. Грудинина - от 7\% до 8\%, за В. В. Жириновского - от 5\% до 6\%; за К. А. Собчак и Г. А. Явлинского - от $1 \%$ до $2 \%$, за остальных кандидатов в Президенты опрошенные не планировали отдавать свои голоса (Выборы-2018, 2018: Электр. ресурс).

Кроме того, за два месяца до выборов в антирейтинге кандидатов лидировала К. А. Собчак: 89,8\% граждан страны сказали, что не отдадут свой голос за данного кандидата (Мониторинг мнений ... , 2018: 174).

За неделю до выборов позиция К. А. Собчак несколько улучшилась, но немного: 82\% опрошенных граждан страны ни при каких обстоятельствах не собирались голосовать за данного кандидата (ВЦИОМ: Собчак, 2018: Электр. ресурс).

Подводя итого, можно сделать следующие выводы:

1) Из восьми кандидатов только у В. В. Жириновского, В. В. Путина и Г. А. Явлинского можно сказать достаточно опыта в принятии участия в выборах Президента: В. В. Путин принял участие в четвертый раз, В. В. Жириновский — в шестой, Г. А. Явлинский - в третий.

Остальные четыре кандидата приняли участие в выборах впервые.

Учитывая данные факты, то обстоятельство, что по результатам социологического опроса ВЦИОМ, П. Н. Грудинин занял второе место после действующего президента по предпочтениям населения страны, можно назвать политической сенсацией и предположить, что в будущем у П. Н. Грудинина достаточно высокие шансы стать значимой политической фигурой в стране;

2) Предвыборные программы кандидатов в Президенты предлагали пути решения различных проблем в стране.

Важно отметить, что предвыборные кампании некоторых кандидатов (например, К. А. Собчак и Г. А. Явлинский) носили общий характер.

Предложения К. А. Собчак и Г. А. Явлинского о пересмотре крымского референдума, по всей видимости, не нашли отклик у избирателей поскольку согласно данным ВЦИОН лишь 1-2\% избирателей планировали отдать 
свой голос за данных кандидатов;

3) На первом этапе предвыборной кампании кандидатов при агитации почти полностью отсутствовала публичная политическая реклама. Во время теледебатов кандидаты в основном в своих выступлениях ограничились общими фразами по своим предвыборным программам;

4) Из восьми кандидатов в Президенты, на основе социологических опросов ВЦИОМ, наиболее эффективно предвыборную кампанию провел В. В. Путин.

По мнению Ю. Р. Бочарова, В. В. Путина планировал получить поддержку 65-75\% избирателей, то есть результат, соответствующий рейтингу действующего Президента (Бочаров, 2018: 148). Поскольку, после подведения итогов выборов стало известно, что В. В. Путин получил 76,69\% голосов избирателей, очевидно, что данная задача выполнена (Выборы-2018: результаты, 2018: Электр. ресурс).

На втором месте - П. А. Грудин. Результат, В. В. Жириновского сложно назвать очень успешным, поскольку данный кандидат планировал набрать 30 \% голосов избирателей страны (Жириновский спрогнозировал свой результат, 2017: Электр. ресурс).

Однако, после утверждения итогов голосования, стало известно, что лишь 5,65\% граждан страны отдели свой голос за В. В. Жириновского (Выборы-2018: результаты, 2018: Электр.ресурс).

По данным социологических опросов ВЦИОМ, К. А. Собчак стала лидером антирейтинга среди кандидатов в Президенты.

Таким образом, можно сделать вывод, что предвыборные программа и кампания К. А. Собчак не нашли положительного отклика у российских избирателей.

В целом, вероятно, вряд ли возможно назвать яркими и запоминающими предвыборные кампании большинства кандидатов в Президенты.

\section{СПИСОК ЛИТЕРАТУРЫ}

Бочаров, Ю. Р. (2017) Операция «преемник» или «чистые» выборы? // Власть. № 5. С. 148-152.

Булгак, О. В. (2013) Стратегии избирательной кампании на примере президентских выборов 4 марта 2012 года // Вестник Нижегородского университета Н. И. Лобачевского. № 2(1). С. 261-265.

В России не ведется активной агитации на выборах президента, заявили в КГИ (2018) [Электронный ресурс] // МИА «Россия сегодня». 12 февраля. URL: https://ria.ru/election2018_news/20180212/1514427704.html (дата обращения: 12.03.2018).

В России официально началась президентская избирательная кампа- 
ния (2017) [Электронный ресурс] // ИА TACC. 18 декабря. URL: http://tass. ru/politika/4820154 (дата обращения: 06.03.2018).

ВЦИОМ: Собчак обладает наивысшим антирейтингом среди кандидатов в президенты (2018) [Электронный ресурс] // Рамблер. 12 марта. URL: https://news.rambler.ru/politics/39334547/?utm_content=rnews\&utm_ medium=read_more\&utm_source=copylink (дата обращения: 20.03.2018).

Выборы-2018 (2018) [Электронный ресурс] // Всероссийский центр изучения общественного мнения URL: https://www.kommersant.ru/ doc/3572283 (дата обращения: 19.03.2018).

Выбор России: об итогах выборов Президента Российской Федерации 2012 года (Беседа с И. М. Ильинским) // Знание. Понимание. Умение. № 2. C. 3-9.

Выборы Президента России - 2018: два месяца до дня голосования // Мониторинг общественного мнения: Экономические и социальные перемены. 2018. № 1. С. 174-176.

Выборы-2018: результаты голосования и явка (2018) [Электронный ресурс] // Информационное агентство «РБК». 18 марта. URL: https://www. rbc.ru/politics/18/03/2018/5aa652d49a79470accef8c29 (дата обращения: 04.04.2018).

Жириновский спрогнозировал свой результат на президентских выборах (2017) [Электронный ресурс] // Рамблер. 30 октября. URL: https:// news.rambler.ru/politics/38281659/?utm_content=rnews\&utm_medium=read_ more\&utm_source=copylink (дата обращения: 04.04.2018).

Кандидат на вырост: зачем бизнес-омбудсмену Титову участие в выборах (2017) [Электронный ресурс] // Информационное агентство «РБК». 26 ноября. URL: https://www.rbc.ru/politics/26/11/2017/5a1a76609a794722 7 еа34204 (дата обращения: 11.03.2018).

Кандидаты в кандидаты (2017) [Электронный ресурс] // Информационное агентство «РБК». 26 декабря. URL: https://www.rbc.ru/photoreport/20 /12/2017/5a3a39c89a794734db31cdd1 (дата обращения: 11.03.2018).

Максим Сурайкин: вперед, в светлое советское прошлое (2018) [Электронный ресурс] // MИA «Россия сегодня». 08 февраля. URL: https://ria. ru/election2018_news/20180208/1514129863.html (дата обращения: 11.03.2018).

Программные заявления: что предлагают избирателям кандидаты в президенты России (2017) [Электронный ресурс] // Телевизионная сеть RT.27 декабря. URL: https://russian.rt.com/russia/article/463909-programmikandidati-vibori-prezident (дата обращения: 07.03.2018).

Путин-2018: главные особенности кампании (2017) [Электронный ресурс] // Сетевое издание «Актуальные комментарии». 6 декабря. URL: http:// 
actualcomment.ru/putin-2018-glavnye-osobennosti-kampanii-1712061303. html (дата обращения: 07.03.2018).

Саитова, Н. Н. (2013) Динамика современно политической рекламы в России на материале президентских выборов в 2012 году // Пробелы в российском законодательстве. № 2 С. 266-272.

Сергей Бабурин обнародовал свою предвыборную программу кандидата в президенты РФ (2018) [Электронный ресурс] // 1RRE - информационно-аналитический портал. 03 февраля. URL: http://www.1rre. ru/70057-sergej-baburin-obnarodoval-svoyu-predvybornuyu-programmukandidata-v-prezidenty-rf.html (дата обращения: 07.03.2018).

Теледебаты кандидатов в президенты подошли к концу Можно ли кого-то из участников назвать победителем (2018) [Электронный ресурс] // Коммерсантъ. 16 марта. URL: https://www.kommersant.ru/doc/3572283 (дата обращения: 12.03.2018).

ЦИК завершил регистрацию кандидатов в президенты (2018) [Электронный ресурс] // ИА ТАСС. 8 февраля. URL: http://tass.ru/politika/4940433 (дата обращения: 07.03.2018).

Дата поступления: 18.04.2018 2.

Махора Екатерина Витальевна - аспирант кафедры философии, культурологии и политологии Московского гуманитарного университета. Адрес: 111395, Россия, г. Москва, ул. Юности, д. 5 . Тел.: +7 (985) 265-43-97. Эл. адрес: katrinmak17@rambler.ru. Научный руководитель — д-р полит. н., профессор В. И. Буренко.

Makhora Ekaterina Vitalievna, Postgraduate Student, Department of Philosophy, Culturology and Politology, Moscow University for the Humanities. Postal address: 5, Yunosti St., Moscow, Russian Federation, 111395. Tel.: +7 (985) 265-43-97. E-mail: katrinmak17@rambler.ru. Scientific Adviser - V. I. Burenko, Doctor of Politology, Professor

\section{Для цитирования:}

Махора Е. В. Предвыборные кампании кандидатов в Президенты Российской Федерации (2017-2018 гг.)[Электронный ресурс] // Научные труды Московского гуманитарного университета. 2018. № 3. URL: http://journals. mosgu.ru/trudy/article/view/748 (дата обращения: дд.мм.гг.). DOI: 10.17805/ trudy.2018.3.11 